\title{
Association between telomere length and CYPI9 TTTA repetition polymorphism in healthy and breast cancer-diagnosed women
}

This article was published in the following Dove Press journal:

Breast Cancer - Targets and Therapy

13 January 2017

Number of times this article has been viewed

\section{Blanca Murillo-Ortiz' Sandra Martínez-Garza' David Suárez García' Rosa del Carmen Castillo Valenzuela ${ }^{2}$ Juan Francisco García Regalado ${ }^{2}$ Gerardo Cano Velázquez'}

'Institute Mexican of Social Security, Department Oncology, Unit of Research in Clinical Epidemiology, ${ }^{2}$ Department of Medical Sciences, University of Guanajuato, León Guanajuato, Mexico
Correspondence: Blanca Murillo-Ortiz Instituto Mexicano del Seguro Social, Servicio de Oncología, Unidad Médica de Alta Especialidad, No I del Bajío, Unidad de Investigación en Epidemiología Clínica, B López Mateos Esq Insurgentes S/N, Colonia Los Paraísos, CP 37320, León, Guanajuato, México

Tel/fax +52 4777183039

Email bomo907@hotmail.com
Introduction: Several studies have reported an increase in breast cancer (BC) risk when patients are carriers of the CYP19 TTA polymorphism with $\geq 10$ repeats; moreover, it has been reported that telomere length is associated with a higher susceptibility of developing cancer.

Objective: The objective of this study was to understand the relationship between CYP19 TTTA repetition polymorphism and telomere length and its effects on serum estradiol, estrone and follicle-stimulating hormone (FSH).

Materials and methods: A total of 180 postmenopausal healthy and $70 \mathrm{BC}$-diagnosed women were included. Telomere length was determined through real-time quantitative polymerase chain reaction, and aromatase polymorphism was analyzed through DNA; both samples were obtained from circulating leukocytes. Serum estrone, estradiol and FSH were determined by enzyme-linked immunosorbent assay.

Results: Patients with a $\mathrm{BC}$ diagnosis showed $>10$ repetitions more frequently, compared with that of healthy women $\left(50 \%\right.$ vs $\left.23 \%, \chi^{2}=11.44, p=0.0007\right)$. A significant difference in telomere length between healthy and $\mathrm{BC}$ women was observed ( $5,042.7 \mathrm{vs} 2,256.7 \mathrm{pb}, Z=4.88$, $p<0.001)$. CYP19 TTTA repeat polymorphism was associated with serum levels of estradiol and estrone in both groups, being higher in those with $>10$ repeats. Moreover, telomere length showed an inverse relationship with the number of repeats of the aromatase polymorphism in healthy women $\left(R^{2}=0.04, r=-0.24\right)$; in contrast, $\mathrm{BC}$ patients did not display this relationship. In addition, telomere length presented an inverse relationship with serum levels of estradiol and estrone in $\mathrm{BC}$ patients $(p=0.02)$.

Conclusion: Telomere length is shorter in BC patients than in healthy patients. The CYP19 TTTA repeat polymorphism is associated with serum levels of estradiol and estrone in both healthy women and $\mathrm{BC}$ patients, being higher in those with polymorphism carriers $>10$ repeats. Telomere length has an inverse correlation with the number of repeats of the aromatase polymorphism in healthy women but not in $\mathrm{BC}$ women. Estradiol and estrone levels in BC women have an inverse relationship with telomere length.

Keywords: telomere length, CYP19 polymorphism, breast cancer

\section{Introduction}

High serum levels of estrogens have been related to the risk of developing breast cancer (BC). ${ }^{1}$ Recently, a meta-analysis that included 14 studies with 20,098 subjects in total demonstrated a strong relationship between CYP19 aromatase polymorphism and BC, although it concluded that more studies are required to evaluate the role of CYP19 in the various carcinogenic mechanisms of BC. Furthermore, it was demonstrated that the higher concentrations of estradiol in situ in $\mathrm{BC}$ are due to catalyzing production 
by intratumoral aromatase. ${ }^{2}$ Several studies have reported an increase in $\mathrm{BC}$ risk when the patients present $\geq 10$ allelic repeats and that $\mathrm{TTTA}^{3}$ is far more frequent in $\mathrm{BC}$ patients compared to healthy controls. ${ }^{4-6}$ Huang et $\mathrm{al}^{7}$ found a higher survival in premenopausal women with $\mathrm{BC}$, positive estrogen receptors and aromatase repetition polymorphism, reporting a survival rate of $89 \%$ vs $68 \%(p=0.003)$ at 8 years compared to those who do not present the repetition variant polymorphism.

Telomeres are specialized structures on the region of each end of the human chromosomes, and their role in genome integrity is essential. Previous studies have reported that shortening of telomere length is associated with a higher risk of developing cancer. ${ }^{8,9}$ Shen et $\mathrm{al}^{10}$ demonstrated that telomere shortening and a low antioxidant diet increase the risk of developing BC. As a result, progressive shortening of the telomere generates instability of the genomic material and by losing its protective portion eventually resulting in carcinogenesis. ${ }^{11}$

In fact, 51 studies were analyzed looking for the relationship of telomere length with the risk of developing cancer. A total of 23,379 cases and 68,792 controls were included. The findings suggest that telomeres play different roles in each cancer type, and, moreover, their length is a risk factor in developing digestive tract cancer and head and neck cancer. ${ }^{12}$

\section{Objective}

The objective of this study was to understand the relationship between CYP19 TTTA repetition polymorphism and telomere length and its effects on serum estradiol, estrone and follicle-stimulating hormone (FSH).

\section{Materials and methods}

We included a total of 180 healthy women who were volunteers recruited from the family medicine department and 70 BC-diagnosed women from the Oncology Department of the High Specialty Medical Unit No. 1 Bajio, Instituto Mexicano del Seguro Social (IMSS), León, Guanajuato, México. The study was performed in accordance with the Declaration of Helsinki of the World Medical Association and was approved by the local bioethics committee of the High Specialty Medical Unit No. 1 Bajio, IMSS, with the registration number $\mathrm{R}$ 2009-1001-35. All patients signed an informed consent form for this investigation.

Telomere length was determined through quantitative real-time polymerase chain reaction (PCR), and aromatase polymorphism was analyzed through genomic DNA; both samples were obtained from circulating leukocytes. The serum levels of estrone, estradiol and FSH were determined by enzyme-linked immunosorbent assay (ELISA). Each group was analyzed according to individual characteristics.

\section{Hormone levels}

The serum levels of estrone, estradiol and FSH were determined by ELISA on a blood draw taken in fasting state of 8 hours.

\section{Telomere length and genotyping of the CYPI9 aromatase polymorphism}

For the measurement of telomere length and genotyping of the CYP19 aromatase polymorphism, we used DNA samples that were extracted from white blood cells. The telomere length was determined by quantitative real-time PCR telomere assay. Genotyping of the CYP19 aromatase polymorphism was determined through PCR.

\section{Telomere measurement}

DNA samples were extracted from circulating white blood cells obtained from a simple blood draw. The ratio of telomere repeat copy number to a single gene copy number (T/S) was determined by a previously described modified version of the quantitative real-time PCR telomere assay. ${ }^{3}$ We performed PCR amplification with oligonucleotide primers designed to hybridize to the TTAGGG and CCCTAA repeats. The final concentrations of reagents in the PCR were 0.2 SYBR Green 1 (Molecular Probes), $15 \mathrm{mM}$ Tris- $\mathrm{HCl} \mathrm{pH}$ 8.0, $50 \mathrm{mM} \mathrm{KCl,} 2 \mathrm{mM} \mathrm{MgCl}$, $0.2 \mathrm{mM}$ each dNTP, $5 \mathrm{mM}$ dithiothreitol, $1 \%$ dimethyl sulfoxide and 1.25 U AmpliTaq Gold DNA Polymerase. The final telomere primer concentrations were tel 1,270 nM and tel 2,900 $\mathrm{nM}$. The final 36B4 (single copy gene) primer concentrations were $36 \mathrm{~B} 4 \mathrm{u}, 300 \mathrm{nM}$ and 36B4d, $500 \mathrm{nM}$. The primer sequences (written $5^{\prime} \rightarrow 3^{\prime}$ ) were tel 1 , GGTTTTTGAGGGTGAGGGTGAGGGTGAGGGTGAGGGT; tel 2, TCCCGACTATCCCTATCCCTATCCCTATCCCTATCCCTA; 36B4u, CAGCAAGTGGGAAGGTGTAATCC and 36B4d, CCCATTCTATCATCAACGGGTACAA. All PCRs were performed on a LightCycler $^{\circledR} 1.5$ (Hoffman-La Roche Ltd.). The thermal cycling profile for both amplicons began with a $95^{\circ} \mathrm{C}$ incubation for $3 \mathrm{~min}$ to activate the AmpliTaq Gold DNA Polymerase. The telomere PCR conditions were 40 cycles at $95^{\circ} \mathrm{C}$ for $15 \mathrm{~s}$ and at $54^{\circ} \mathrm{C}$ for $2 \mathrm{~min}$; for $36 \mathrm{~B} 4 \mathrm{PCR}$, the conditions were 40 cycles at $95^{\circ} \mathrm{C}$ for $15 \mathrm{~s}$ and at $58^{\circ} \mathrm{C}$ for $1 \mathrm{~min}$. The LightCycler ${ }^{\circledR} 1.5$ was then used to generate the standard curve for each run and to determine the dilution factors of standards corresponding to the amounts of $\mathrm{T}$ and $\mathrm{S}$ in each sample. 


\section{DNA isolation and genotyping}

DNA was isolated from white cells using standard phenolchloroform method. PCR was performed in $25 \mu \mathrm{L}$ reaction containing $80 \mathrm{ng}$ of genomic DNA, $1 \times$ PCR buffer, $200 \mathrm{~nm}$ dNTP, 2 mM de $\mathrm{MgCl}_{2}, 100$ pmol of each primer (5'-GCAGGTACTTAGTTAGCTAC-3' and 5'-TTACAGTGAGCCAAGGTGCT-3') and 2 units of Taq DNA polymerase (Thermo Fisher Scientific). The amplification conditions were as follows: 5 minutes of the initial denaturation at $94^{\circ} \mathrm{C}$ followed by 30 cycles at $94^{\circ} \mathrm{C}$ for $1 \mathrm{~min}$, at $53^{\circ} \mathrm{C}$ for $1 \mathrm{~min}$ and at $72^{\circ} \mathrm{C}$ for $4 \mathrm{~min}$ and a final extension at $72^{\circ} \mathrm{C}$ for $10 \mathrm{~min}$. After the PCR process, an aliquot was electrophoresed through a $10 \%$ polyacrylamide denaturing gel to separate fragments followed by silver staining. The size of each allele was determined using CSF1PO as allelic ladder (Figure 1).

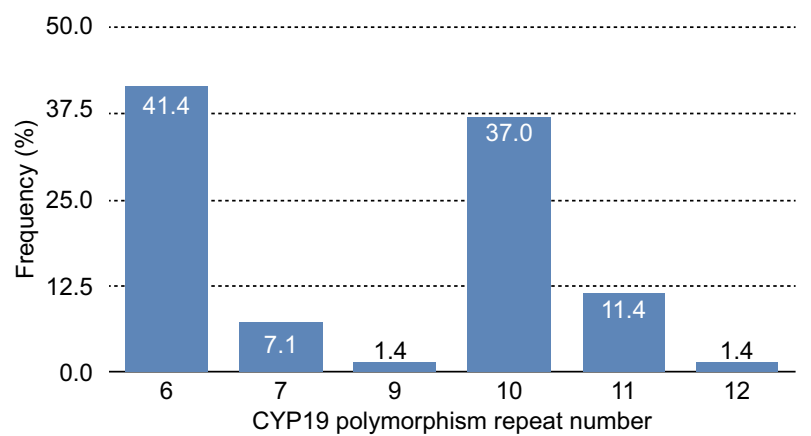

Figure I CYPI9 aromatase polymorphism frequency by number of repeats in BCdiagnosed women.

Abbreviation: $\mathrm{BC}$, breast cancer.

\section{Statistical analysis}

Fisher's exact test was used to determine the association between patients with $\mathrm{BC}$ and $>10$ repeats, which were more common compared to healthy women. Linear regression analysis was performed to determine the relationship between telomere length and estrone, estradiol and FSH levels. Correlations were tested by means of Spearman's rank correlation coefficients, comparing the telomere length between healthy women and BC patients. Mann-Whitney $U$ test was used to compare the telomeric length between healthy women and BC-diagnosed women. $p<0.05$ was considered significant.

\section{Results}

The mean age of the $\mathrm{BC}$ patients was $58.74 \pm 12$ years, and the body mass index (BMI) was $30 \mathrm{~kg} / \mathrm{m}^{2}(21.69-37.10) ; 40 \%$ of them were classified as obese and $51 \%$ as overweight. BC clinical stages 2 and 3 were the most frequent at diagnosis $(37.14 \%$ and $41.42 \%$, respectively). The most frequent histological diagnoses were ductal carcinoma $(60 \%)$, lobular carcinoma $(24.28 \%)$ and others $(11.0 \%)$. Healthy women had a mean age of $59 \pm 11$ years and a BMI of $29.8 \pm 7.1 \mathrm{~kg} / \mathrm{m}^{2}$. The clinical characteristics and hormone levels of the patients are shown in Table 1 .

\section{Distribution and frequency of the CYPI9 aromatase polymorphism}

A total of $\geq 10$ repeats were more common in $\mathrm{BC}$ patients compared with the healthy women $\left(50 \%\right.$ vs $23 \%, \chi^{2}=11.44$, $p=0.0007)$.

Table I Clinical parameters of BC-diagnosed women and healthy women.

\begin{tabular}{|c|c|c|c|}
\hline Clinical parameter & BC-diagnosed women $(n=70)$ & Healthy women $(n=180)$ & $p$ \\
\hline Age (years) & $58.74 \pm 12$ & $59.0 \pm 11$ & 0.88 \\
\hline BMI $\left(\mathrm{kg} / \mathrm{m}^{2}\right)$ & $30 \pm 7.1$ & $29.8 \pm 7.1$ & 0.92 \\
\hline \multicolumn{4}{|l|}{ Hormonal levels } \\
\hline Estradiol (pg/mL) & $19.89 \pm 5.96$ & $17.6 \pm 9.6$ & 0.09 \\
\hline $\mathrm{FSH}(\mathrm{Ul} / \mathrm{L})$ & $43.90 \pm 18.99$ & $58.3 \pm 5.6$ & 0.06 \\
\hline Estrone (pg/mL) & $25.4 \pm 4.8$ & $37.5 \pm 12.0$ & 0.17 \\
\hline \multicolumn{4}{|l|}{ Clinical stage, n (\%) } \\
\hline I & $4.28(3)$ & & \\
\hline II & $37.14(26)$ & & \\
\hline III & $4 I .42(29)$ & & \\
\hline IV & $17.14(12)$ & & \\
\hline \multicolumn{4}{|l|}{ Histologic grade, n (\%) } \\
\hline $\mathrm{I}$ and 2 & $14(20)$ & & \\
\hline 3 & $56(80)$ & & \\
\hline \multicolumn{4}{|l|}{ Histologic type, n (\%) } \\
\hline Ductal & $42(60.0)$ & & \\
\hline Lobular & $17(24.2)$ & & \\
\hline Others & II (5.7) & & \\
\hline \multicolumn{4}{|c|}{ Hormonal receptors positive (\%) } \\
\hline Estrogen & 88 & & \\
\hline Progesterone & 89 & & \\
\hline
\end{tabular}

Abbreviations: BC, breast cancer; BMI, body mass index; FSH, follicle-stimulating hormone. 
In the healthy women's group, the most common polymorphism was 6 repeats followed by 7 repeats; $23 \%$ of healthy women had $>10$ repeats and $71 \%$ had $<10$ repeats of the CYP19 polymorphism. In BC patients also, the most common polymorphism was 6 repeats $(41.4 \%)$, followed by 10 repeats (37\%; Figure 1); in fact, $50.1 \%$ had $>10$ repeats of TTTA and $49.9 \%$ had $<10$ repeats of TTTA $\left(\chi^{2}=11.44, p=0.0007\right.$; Figure 2). The different number of repetitions found in each group of the acrylamide gel is shown in Figure 3.

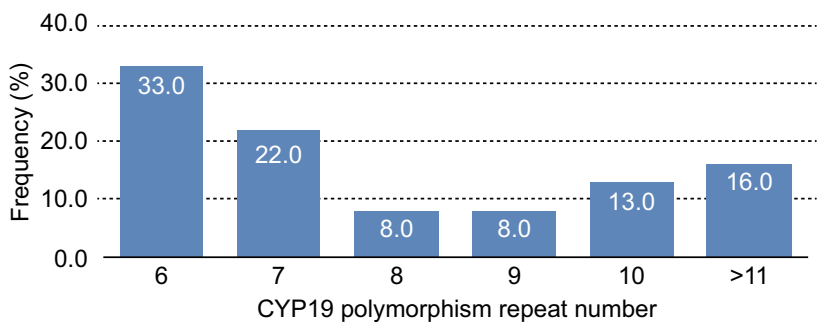

Figure 2 CYPI 9 aromatase polymorphism frequency by number of repeats in healthy women.

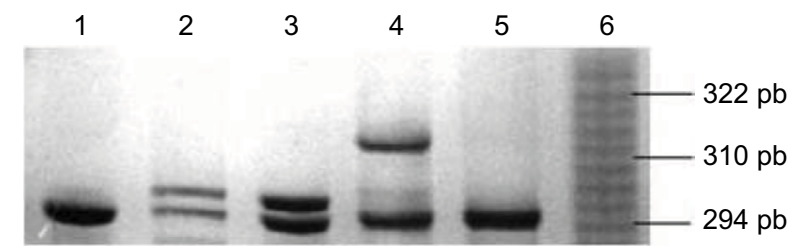

Figure 3 CYPI9 aromatase polymorphism frequency by number of repeats (acrylamide gel 10\% with $7 \mathrm{M}$ of urea).

Note: Lane I: homozygote (TTTA)7, lane 2: heterozygote (TTTA)7/(TTTA)8, lane 3: heterozygote (TTTA)6/(TTTA)7, lane 4: heterozygote (TTTA)6/(TTTA) 10, lane 5: homozygote (TTTA)6 and lane 6: allelic marker.

\section{Telomeric length}

A significant difference was obtained when the telomere length was compared between healthy and $\mathrm{BC}$ patients $(5,042.7$ vs $2,256.7 \mathrm{pb}, Z=4.88, p<0.001)$, which is shown in Figure 4. We proved the existence of a significantly and anticipated telomere shortening in BC patients. Spearman's coefficient analysis applied on the healthy women's group demonstrated an inverse correlation between the number of repetitions and telomere length $\left(R^{2}=0.04, r=-0.24\right)$; on the other hand, this correlation was not observed in the analysis of $\mathrm{BC}$ patients' group.

\section{Hormone levels}

Estradiol, estrone and FSH serum levels were determined, and the relationship between them, telomere length and the number of repeats were obtained through linear regression models.

\section{Hormone levels in healthy women}

In healthy women with $>10$ repeats of the polymorphism, the levels of estrone $(Z=1.74, p=0.04)$ and estradiol $(Z=1.78$, $p=0.03)$ were far higher than those in patients with less repetitions.

A correlation analysis between telomere length and estrone levels showed a positive relationship $\left(R^{2}=0.13\right.$, $\beta=55.93, t=2.5, p=0.01)$; there was no evidence of relationship between telomere length and estradiol levels $\left(R^{2}=0.32\right.$, $\beta=-22.31, t=-1.16, p>0.05)$ as shown in Figure 5. There

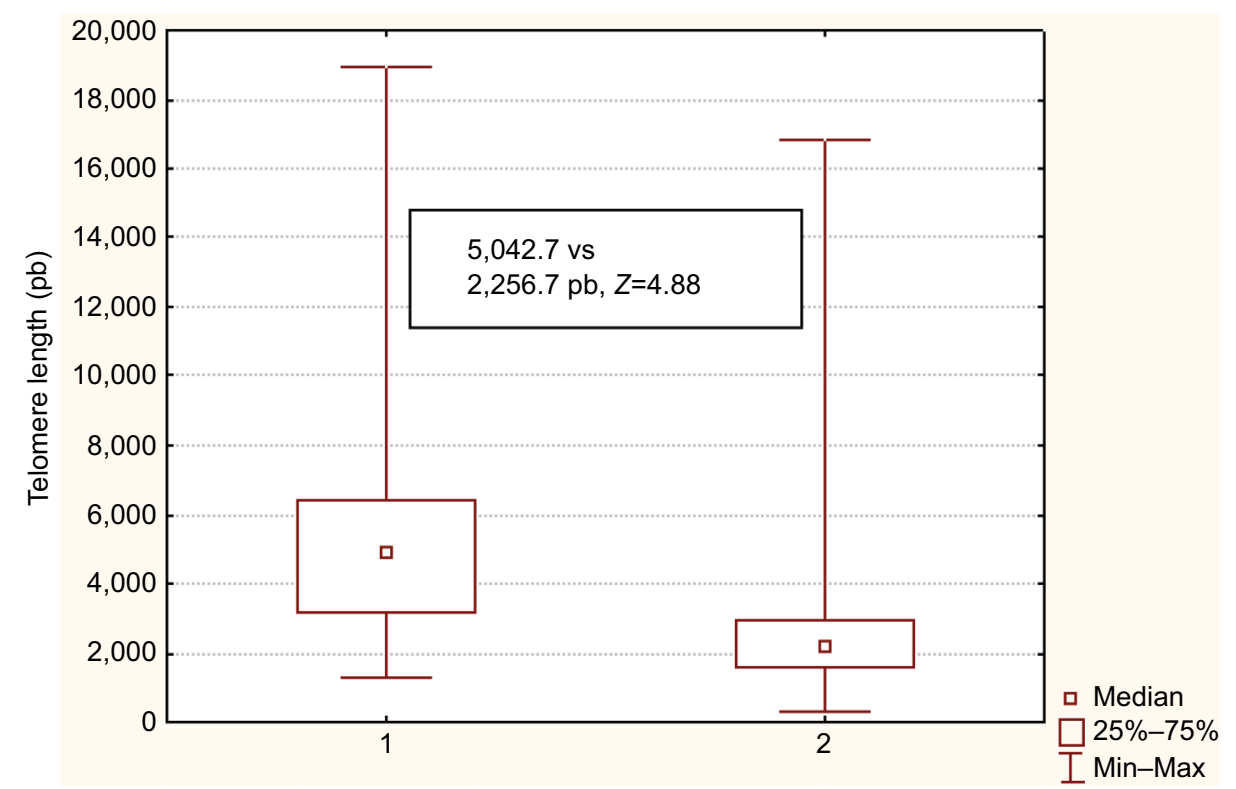

Figure 4 Telomere length comparison between healthy women (group I) and BC-diagnosed women (group 2).

Notes: Significant difference is shown between groups (calculated using Mann-Whitney $U$ test). $p<0.05$ was considered significant.

Abbreviations: BC, breast cancer; Min, minimum, Max, maximum. 


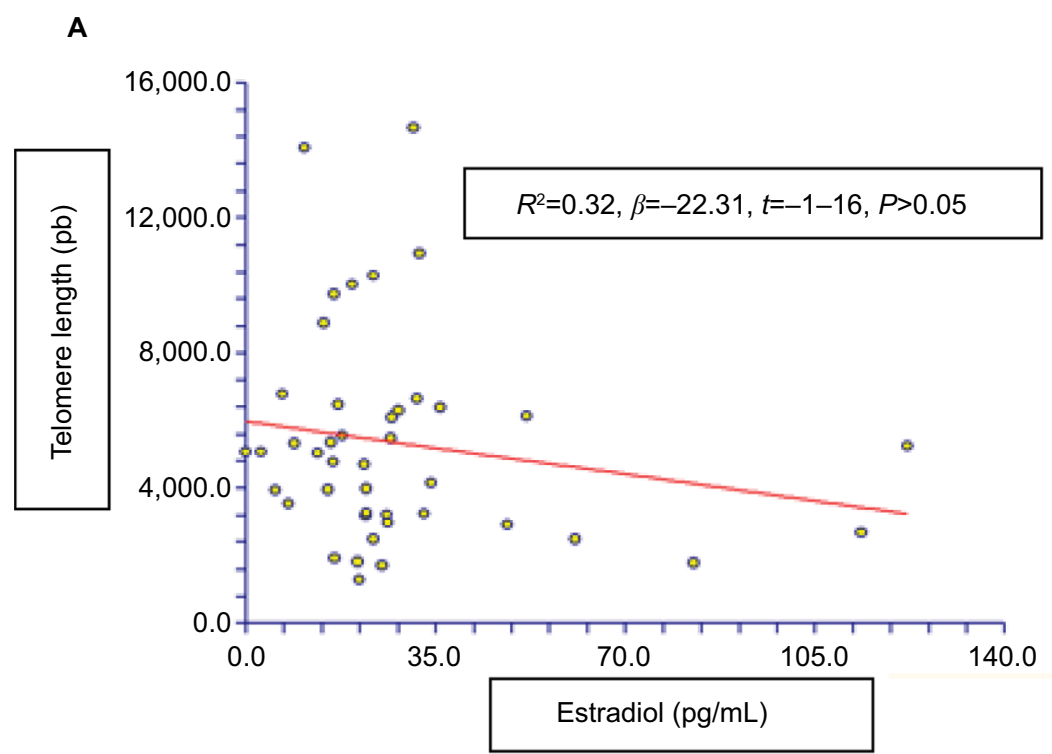

B

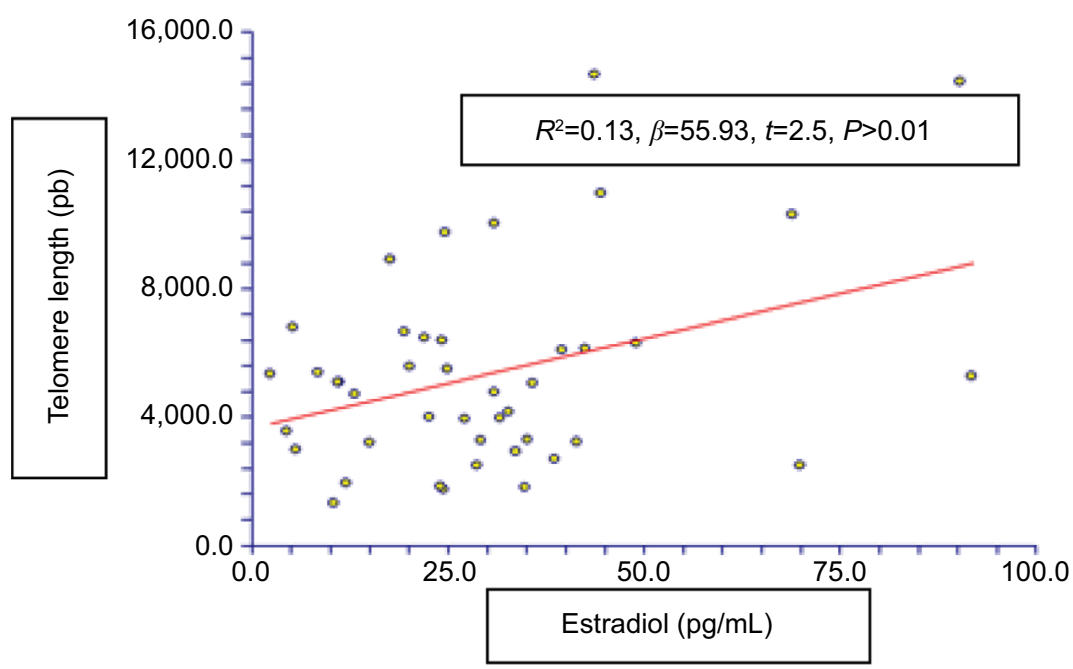

Figure 5 The relationship between telomere length and serum levels of $(\mathbf{A})$ estradiol $(\mathrm{pg} / \mathrm{mL})$ and $(\mathbf{B})$ estrone $(\mathrm{pg} / \mathrm{mL})$ in healthy women.

was no significant relationship with FSH levels $(\beta=7.21$, $t=0.37, p>0.05)$.

\section{Hormone levels in BC-diagnosed women}

Higher levels of estrone $(p=0.04)$ and estradiol $(p=0.02)$ were also observed in the $\mathrm{BC}$ patients' group with $>10$ repeats compared to those who had $<10$ repeats.

Telomere length showed an inverse and significant relationship with serum estrone levels $(p=0.02)$.

\section{Discussion}

In the present study, we demonstrated that in healthy and BC-diagnosed women, a significant relationship between serum estrone and estradiol levels and $>10$ repeats of CYP19 aromatase polymorphism exists $(Z=1.74, p=0.04, Z=1.78$, $p=0.03$ ).

We also found evidence that suggests that estrone levels and telomere length had a positive relationship, which is consistent with previous reports that proposed that telomere length is directly determined by the influence of estrogen levels, due to its action on telomerase activity and on the telomerase reverse transcriptase gene expression in cancer culture cells. ${ }^{8}$

Several studies report shorter telomeres in BC patients than in healthy controls. ${ }^{13,14}$ We could also ascertain a difference of 2,700 base pairs in length between healthy and BC patients, with the difference being higher in the former ones $(p=0.001)$. The current study demonstrates that the telomere 
length in healthy patients, without external influence such as genetic disruption that is found in cancer or its treatment, is directly influenced by the levels of circulating estrogens; furthermore, the levels of the latter are related to the number of repeats of aromatase polymorphism, which implies that in healthy women, telomeric length is influenced by TTTA polymorphism.

There is evidence that demonstrates that hormones can regulate telomerase activity in specific tissues, especially in the endometrium, which expresses telomerase activity even though its somatic origin is tightly regulated during menstrual cycle phases, suggesting a control mechanism of the telomerase by sexual steroids. ${ }^{15}$ This influence has been reported since 1999 by Kyo et al who demonstrated that telomere length in healthy premenopausal women was longer than males paired by age, suggesting that the difference between them was due to estrogen influence.

It has been demonstrated in mouse models that the cell's telomeric length of the adrenal gland is shortened when estrogen knockout mice are studied, and moreover, this effect is reversed by replacement therapy with external estrogens for 3 weeks, which reactivate telomerase activity. ${ }^{16}$ Again, it has been reported that postmenopausal women under treatment of hormonal replacement therapy had longer telomeres than postmenopausal women without this treatment. The influence of estrogens on the progression of cancer, especially $\mathrm{BC}$, is also well known. In postmenopausal women, the origin of these estrogens is the peripheral conversion of adrenal androgens to estrone, catalyzed by aromatase enzyme, and furthermore, the CYP19 polymorphism with TTTA tandem repeats of $>10$ is related to an increase in the risk of developing BC. Previously, Haiman et al ${ }^{17}$ showed that CYP19 haplotypes correlated with circulating estrogen levels ( $r=0.83-0.466)$, although a relationship between the latter and cancer development could not be demonstrated.

We found that estrone levels on patients with more than 10 repeats on aromatase's polymorphism were significantly higher than those with less than 10 repetitions $(p=0.04)$, association that also was obtained with estradiol levels ( $p=0.03$ ), we suggest an association between these hormones levels and number of repetitions on telomere's length, given that a higher repetition results on higher levels of circulating estrone and subsequently a longer telomere's length on healthy women $(r=0.2, p=0.01)$.

As previously reported by several studies regarding the relationship between CYP19 polymorphism and $\mathrm{BC}^{10,18-23}$; we ascertain this relationship in $\mathrm{BC}$ patients with $>10$ repeats in the aromatase gene $(p=0.05)$. Moreover, the results found in the current study demonstrate that $\mathrm{BC}$ patients have significantly shorter telomeres than healthy women with a mean difference of 2,700 base pairs. The latter situation has been practically taken as a consensus by most researchers.

Taking this fact as a prognostic factor for the development of cancer, it seems that telomeric shortening is an important part in cancer progression from the point that it gets to a critical moment as the repair and senescence mechanisms fail, ending in chromosome instability and carcinogenesis, to which follows telomerase reactivation that aids in perpetuation of cellular immortality, which in fact generates shorter telomeres than in healthy cells. ${ }^{24}$ Nevertheless, recently some reports demonstrate that in early stages, the telomeres found on $\mathrm{BC}$ and renal cell carcinoma patients are larger than those in healthy controls, ${ }^{8,9,13,14}$ which apparently contradicts the results found by De Vivo, Shen, McGrath, but Pooley K et al, but is similar to the results of Pooley et al, ${ }^{9}$ in which there is a difference in telomere length while considering retrospective designs. ${ }^{25}$ It has been proposed, as a justification for these differences, that this is due to telomere shortening influenced by cancer treatment, given that both chemotherapy and radiotherapy cause DNA damage. Until now, there is no certainty on the effect and degree of these therapies on lymphocytes and their sub populations, considering that this study did not show differences in the measurement on patients who received chemotherapy, hormonal therapy or radiotherapy.

This is the first report of a study designed with an aim of establishing a relationship between telomere length in healthy postmenopausal women and BC-diagnosed patients and CYP19 aromatase gene polymorphism. Telomeric length and aromatase polymorphism have been considered separately as risk predictors for developing $\mathrm{BC}$, but the association between them has not been investigated. More studies analyzing both factors are needed.

\section{Conclusion}

First and foremost, there is a significant difference in telomere length between healthy women and BC-diagnosed women. The CYP19 TTTA polymorphism is associated with serum levels of estradiol and estrone in healthy and BC-diagnosed women, being higher in those with $>10$ tandem repeats. Notably, telomere length presents an inverse correlation with the number of repetitions in healthy women but not in $\mathrm{BC}$ patients. Moreover, telomere length has an inverse relationship with estradiol and estrone levels in BC patients. The current study contributes to support the important evidence on the role that fatty acid aromatization has on the elevation of serum levels of both estrone and estradiol and, consequently, 
a direct effect on telomere length, which is an important risk factor for the development of BC.

\section{Disclosure}

The authors report no conflicts of interest in this work.

\section{References}

1. Kitahara CM, Flint AJ, Berrington de Gonzalez A, et al. Association between class III obesity (BMI of $40-59 \mathrm{~kg} / \mathrm{m} 2$ ) and mortality: a pooled analysis of 20 prospective studies. PLOS Med. 2014.

2. Bulun SE, Sebastian S, Takayama K, Suzuki T, Sasano H, Shozu M. The human CYP19 (aromatase P450) gene: update on physiologic roles and genomic organization of promoters. $J$ Steroid Biochem Mol Biol. 2003;86(3-5):219-224.

3. Cawthon RM. Telomere measurement by quantitative PCR. Nucleic Acids Res. 2002;30(10):47e.

4. Pineda B, García-Pérez MÁ, Cano A, Lluch A, Eroles P. Associations between aromatase CYP19 rs 10046 polymorphism and breast cancer risk: from a case-control to a meta-analysis of 20,098 subjects. PLoS One. 2013;8(1):e53902.

5. Kristensen VN, Harada N, Yoshimura N, et al. Genetic variants of CYP19 (aromatase) and breast cancer risk. Oncogene. 2000;19(10):1329-1333.

6. Zhang I, Gu I, Qian B, et al. Association of genetic polymorphisms of ER-alpha and the estradiol-synthesizing enzyme genes CYP17 and CYP19 with breast cancer risk in Chinese women. Breast Cancer Res Treat. 2009;114(2):327-338.

7. Huang CS, Kuo SH, Lien HC, et al. The CYP19 TTTA repeat polymorphism is related to the prognosis of premenopausal stage I-II and operable stage III breast cancers. Oncologist. 2008;13(7):751-760.

8. De Vivo I, Prescott J, Wong JY, Kraft P, Hankinson SE, Hunter DJ. A prospective study of relative telomere length and postmenopausal breast cancer risk. Cancer Epidemiol Biomarkers Prev. 2009;18(4):1152-1156.

9. Pooley KA, Sandhu MS, Tyrer J, et al. Telomere length in prospective and retrospective cancer case-control studies. Cancer Res. 2010;70(8): 3170-3176.

10. Shen J, Gammon MD, Terry MB, et al. Telomere length, oxidative damage, antioxidants and breast cancer risk. Int J Cancer. 2009;124(7): $1637-1643$.

11. Zhu X, Han W, Xue W, et al. The association between telomere length and cancer risk in population studies. Sci Rep. 2016;6:22243.
12. Wu X, Amos CI, Zhu Y, et al. Telomere dysfunction: a potential cancer predisposition factor. $J$ Natl Cancer Inst. 2003;95(16):1211-1218.

13. McGrath M, Wong J, Michaud D, Hunter D, Vivo D. Telomere length, cigarette smoking, and bladder cancer risk in men and women. Cancer Epidemiol Biomarkers Prev. 2007;16(4):815-819.

14. Shen J, Terry M, Gurvich I, Liao Y, Senie R, Santella R. Short telomere length and breast cancer risk: a study in sister sets. Cancer Res. 2007; 67(11):5538-5544.

15. Kyo S, Takakura M, Kanaya T, et al. Estrogen activates telomerase. Cancer Res. 1999;59(23):5917-5921.

16. Bayne S, Jones M, Li H, Pinto A, Simpson E, Liu J. Estrogen deficiency leads to telomerase inhibition, telomere shortening and reduced cell proliferation in the adrenal gland of mice. Cell Res. 2008;18(11): 1141-1150.

17. Haiman C, Dossus L, Setiawan V, et al. Genetic variation at the CYP19A1 locus predicts circulating estrogen levels but not breast cancer risk in postmenopausal women. Cancer Res. 2007;67(5):1893-1897.

18. Ahsan H, Chen Y, Whittemore AS, et al. A family-based genetic association study of variants in estrogen-metabolism genes COMT and CYP1B1 and breast cancer risk. Breast Cancer Res Treat. 2004;85(2): 121-131.

19. Hu M, Xie W, Xiong B, et al. Study on the relationship between polymorphisms of genes (CYP17, CYP19 and SULT1A1) and susceptibility to breast cancer in Chinese women. Zhonghua Liu Xing Bing Xue Za Zhi. 2006;27(4):351-355.

20. Miyoshi Y, Iwao K, Ikeda N, Egawa C, Noguchi S. Breast cancer risk associated with polymorphism inCYP19 in Japanese women. Int $J$ Cancer. 2000;89(4):325-328.

21. Okobia MN, Bunker CH, Zmuda JM, et al. Simple tandem repeat (TTTA) $n$ polymorphism in CYP19 (aromatase) gene and breast cancer risk in Nigerian women. $J$ Carcinog. 2006;5(1):12.

22. Ribeiro FS, da Fonte de Amorim LM, de Almeida Simão T, Mendonça GA, de Moura Gallo CV, Pinto LFR. CYP19 (TTTA)n polymorphism and breast cancer risk in Brazilian women. Toxicol Lett. 2006;164(1): 90-95.

23. Saharia A, Guittat L, Crocker S, et al. Flap endonuclease 1 contributes to Telomere stability. Curr Biol. 2008;18(7):496-500.

24. McGlynn LM, Stevenson K, Lamb K. Cellular senescence in pretransplant renal biopsies predicts postoperative organ function. Aging Cell. 2009;8(1):45-51.

25. Svenson U, Nordfjall K, Stegmayr B, et al. Breast cancer survival is associated with Telomere length in peripheral blood cells. Cancer Res. 2008;68(10):3618-3623.
Breast Cancer - Targets and Therapy

\section{Publish your work in this journal}

Breast Cancer - Targets and Therapy is an international, peerreviewed open access journal focusing on breast cancer research, identification of therapeutic targets and the optimal use of preventative and integrated treatment interventions to achieve improved outcomes, enhanced survival and quality of life for the cancer patient.

\section{Dovepress}

The manuscript management system is completely online and includes a very quick and fair peer-review system, which is all easy to use. Visit http://www.dovepress.com/testimonials.php to read real quotes from published authors. 